\title{
Effects of Pranayama on Human Memory Improvement
}

\author{
Nivriti Singh ${ }^{1}$, Prabodh Bansal ${ }^{2}$, Shikha saxena ${ }^{3}$, Suparna Ghosh ${ }^{4}$ \\ ${ }^{1}$ Associate Professor, Rohilkhand Medical College, Bareilly (Uttar Pradesh), ${ }^{2}$ Associate Professor Surgery, Rama \\ Medical College and Research Centre Hapur UP, ${ }^{3}$ Associate Professor, Rohilkhand Medical College, Bareilly UP, \\ ${ }^{4}$ Professor, East Point College of Medical Sciences, Bangalore
}

\begin{abstract}
Aim and Objective: The purpose of this study is to evaluate results of memory scores in normal healthy adult. Brain areas involved in memory such as the hippocampus, the amygdala, the striatum, or the mammillary bodies are thought to be involved in specific types of memory. Pranayama is to control the body function by controlling our breath
\end{abstract}

Materials and Method: This study was conducted in the yoga center on 62 subjects. Subjects were trained for breath holding yoga training. they performed for total of 30 minutes duration daily. At the end of four week the subjects were examined by WECHSLER memory scale.

Observations: The results showed increase in scores of all types of test DSF, DSB, and all are highly significant $\mathrm{P}<0.001$.

Results: All the scores of Wechsler memory scales are highly significant after pranayama.

Conclusion: The repeated measure ANOVA analysis revealed a significant increase in memory. This study concludes that yoga enhances numerical data retrieval mostly as a result of left-brain activation.

Keywords: Digit Span Forward, Digit Span backward.

\section{Introduction}

Pranayama is to control the body function by controlling our breath. Breathing is the most important function of the body. Nasal cycle is alternate patency of both the nostril every two to eight hours ${ }^{1}$. From the physiologic point of view there are two types of memory. Explicit memory and implicit memory. Short term memory lasts in few seconds to minute and longterm memory which stores memories for years and sometimes for life $^{2}$. Working memory is a form of

\footnotetext{
Corresponding Author:

Nivriti Singh

Associate Professor, Department of Physiology,

Rohilkhand Medical College, Bareilly (Uttar

Pradesh)-243006

e-mail:drnivriti@gmail.com
}

short-term memory which keeps data for very short period $^{3}$. We recall it after few minutes without rehearsal capacity of short- and long-term memory can be increased by chunking ${ }^{3}$. Atkison-Shiffrin model $^{3}$ shows the recognition memory task and recall memory task. Memory depend upon encoding and recall ${ }^{4}$.

\section{Material and Method}

This study was conducted in the yoga center. The project was approved by the Institutional Ethics Committee. A code was provided to the subjects to keep their identity closed. Their achievement scores were not disclosed to anywhere. Results of our scores were used only for this research. The study was conducted on 62 Young healthy subject of either gender having good general physical condition with age group 20-40 years with average body mass index.

Subjects with the history of Hypertension, Tuberculosis and major psychiatric illness, Smoking, 
alcohol intake, Long term drug therapy for any disease were not included. Stress was checked by DASS scale and Subject with moderate to very severe either depression, anxiety or stress were not included.

The present study was cohort study on 62 normal subjects, the study started as four-week pranayama breath control training subjects were asked to take deep inhalation through the left nostril and keep the right nostril closed with the ring finger of right hand. Hold the breath for few second and exhale slowly through right nostril keep the left nostril closed subject performed for total of 30 minutes duration daily for 30 days. At the end of four week the subjects were examined by WECHSLER memory scale. The data was analyzed applying repeated measured ANOVA test using statistical software package.

\section{Observations:}

Table 1: Scores of Wechsler Memory Scale before and after

\begin{tabular}{|c|l|c|c|c|}
\hline S.No. & Wechsler Memory Scale & Before & After & P value \\
\hline 1. & Digit Span Forward & $5.34 \pm .11$ & $6.43 \pm .07$ & $<0.0001$ \\
\hline 2. & Digit span backward & $4.34 \pm .02$ & $5.01 \pm .03$ & $<0.0001$ \\
\hline
\end{tabular}

Results of DSF were $\mathrm{t}=65.82 ; \mathrm{df}=112 ; \mathrm{SED}=0,017 \mathrm{P}<0,0001$

Results of DSB were $\mathrm{t}=146.31 ; \mathrm{df}=122$ and $\mathrm{SED}=0.005 \mathrm{P}<0.0001$

The results showed increase in scores of all types of test and all are highly significant $\mathrm{P}<0.0001$. It may be concluded from above mentioned finding of the study that with the intervention of pranayama, Memory performance improves. So, it is suggested that pranayama should become a regular part in our life.

\section{Discussion}

The present study was done to evaluate the memory scores after pranayama training. The study comprised of 62 subjects. The findings of this study reveal that the subjects experienced breath holding yoga module performed better in all two types of WMS test including Digit span forward, Digit span backward. These results are in tune with another study, and found that meditation, practiced over long periods, produces definite changes in perception, attention, and cognition ${ }^{11}$. Other study showed that yoga techniques are helpful in reducing anxiety and stress and improvement in concentration ${ }^{12}$.

Another study has reported that there was a significant improvement in the scores of memory test after both Cyclic meditation and Supine rest or the corpse posture (shavasana) ${ }^{9}$ but the increment was more after $\mathrm{CM}$ compared to the $\mathrm{SR}^{9}$. Another study evaluated in the performance of children in verbal and spatial memory tests, there were two groups, one attending a yoga camp and the other a fine arts camp ${ }^{6}$. The yoga group showed a significant increase of $43 \%$ in spatial memory scores (Multivariate analysis, Tukey test), while control groups showed no change. The results of the above study suggest that yoga practice, postures, yoga breathing, meditation improved delayed recall of spatial information ${ }^{6}$.

Another study showed that the students of yoga group performed better in academics. This study further concluded that low-stress students performed better than high-stress students, these results are similar to our study and proved that stress affects the students performance ${ }^{10}$. Review and literature

Memory can be encoded stored and retrieved. Encoding is the first stage in which we may put information from the world in the form of physical and chemical stimuli. second stage is the storage and third stage is retrieval. Yoga means union in Sanskrit. It is believed that Patanjali was the first to define yoga in third century BC. Different studies have shown that various yoga technique, meditation, pranayama and breathing techniques improve the immediate and spatial human memory. A study has shown that controlled right and left nostril breathing facilitates the performance on spatial and verbal scores ${ }^{5}$.

Another study, six letter cancellation tasks was done with 69 male subjects, ages 18 to 48 years. After the session they were assessed. The techniques used in 
this study were cyclic meditation and supine rest. The results were shown that cyclic meditation brings about a greater improvement in performance in this task. which require selective attention, concentration, visual scanning abilities and respective motor response ${ }^{6 .}$ The results of the study on musician suggested that yoga and meditation may be beneficial as a routine practice to reduce performance anxiety in musicians ${ }^{7}$.

\section{Conclusion and Summary}

This study was undertaken to evaluate the effects of pranayama on Memory performance. this study comprises of 62 healthy, physically active, young normal subjects having 42 male and 20 females. Memory level was assessed by using Wechsler Memory Scale after controlled breathing Pranayama for duration of 30 minutes daily for thirty days.

Previously a study shown the effects of unilateral forced nostril breathing on the intraocular pressures of eyes in 50 adults $^{8}$ in men, the forced breathing through both the right and left nostrils significantly decreased the intraocular pressures of both right and left eyes ${ }^{8}$.

The repeated measure ANOVA analysis revealed a significant increase in memory. This study concludes that yoga enhances numerical data retrieval mostly as a result of left-brain activation.

Ethical Clearance: This study was approved by institutional ethics committee.

Source of Support: Nil.

Conflict of Interest: None.

\section{References}

1. Keuning j. On the nasal cycle. International journal, 1968; 6: 99-136

2. GANONG"s 23 rd edition.

3. Hartshorn K., Rovee-Collier C., Gerhardstein P., Bhatt R.S., Wondoloski T.L., Klein P., Gilch J.,
Wurtzel N., Campos-de Carvalho M. (1998). \& quot; The ontogeny of long-term memory over the first year-and-a-half of life \& quot;. Developmental Psychobiology 32: 69-89.

4. Loftus E F \& amp; Palmer J C. "Reconstruction of automobile destruction: (1974)

5. Miller, G.A. The Magical Number Seven, Plus or Minns Two: Some Limits on our capacity for processing information. Psychological Review, 63, 81-97.(1956),

6. Joshi M, Telles S .Immidiateeffet of right and left nostril breathing on verbal and spatial scores. Ind $\mathrm{j}$ Physiol Pharmacol 2008; 52: 197-200.

7. Manjunnath NK, Telles S . Spatial and Verbal memory test scores following yoga and fine arts for school children, Indian j physiol pharmacy 2004; 48 (3) : 353-356.

8. Wrentz DA Bickford RG, Bloom FE, Shannahoff K. Alternating cerebral hemispheric activity and the lateral action of autonomic nervous function. Human Neurobiol 1983; 2: 39-43.

9. Loftus GR "When a lie becomes memory 's truth: Memory distortion after exposure tomisinformation" Current Directions in psychological science 1: 121123.(1992)

10. N.K. Subbalakshmi, S.K. Saxena, : Immediate effect of 'Nadi -Shodhana Pranayama' on some selected parameters of cardiovascular, pulmonary, and higher functions of brain : Thai journal of physiological sciences; volume 18. No. 2, August 2005

11. Rahi A. Bisht Battery Stress Scale, National Psychological Corporation, Kacheri Ghat, Agra, UP, India. 1987.4/230

12. Sahasi G, Mohan D, Kacker C. Effectiveness of yogic techniques in the management of anxiety. Journal of Personality and Clinical Studies. 1989;1:51-5. 